УДК 330.34, JEL Q43

$10.17213 / 2075-2067-2020-6-217-223$

\title{
АНАЛИЗ И МЕТОДЫ КООРДИНАЦИИ МЕРОПРИЯТИЙ ПО ЭНЕРГОЭФФЕКТИВНОСТИ ЭКОНОМИКИ РЕГИОНОВ
}

\author{
(C) 2020 г. И. Н. Полетаев
}
Институт региональных экономических исследований (ИРЭИ), г. Москва, Россия ООО «Электра», г. Екатеринбург, Россия

Целью исследования является анализ основных задач и мероприятий органов государственного и регионального управления при реализащии региональных программ и мероприятий в области энергосбережения и энергоэффективности.

Методологическую основу исследования представляют исследования мероприятий по повышению эффективности использования энергетических ресурсов, для этого проводится сравнительный анализ и классификация. Информащионной базой исследования послужили нормативно-правовые документы Российской Федераџии в области энергоэффективности.

Результаты исследования. В статье проведен анализ формирования региональных и муниципальных целевых программ по повышению энергоэффективности экономики. Приведены методы малозатратных мероприятий при решении вопросов повышения энергоэффективности: юридические, административные и технологические. Обрашается особое внимание на необходимость координации взаимодействия в совместной деятельности органов государственного управления и структур регионов, независимо от их отраслевой и ведомственной принадлежности и организационно-правовых форм.

Перспективу исследования составляет дальнейшее исследование и углубленный анализ региональных мероприятий по повышению энергоэффективности с иелью определения оптимальных и окупаемых мероприятий для обобщения и разработки современных нормативно-правовых документов.

Ключевые слова: координация; развитие; регион; ресурсы; энергия; энергоэффективность; управление.

\section{ANALYSIS AND METHODS OF COORDINATION OF REGIONAL ENERGY EFFICIENCY MEASURES}

\author{
(C) 2020 I. Yu. Poletaev \\ Institute for Regional Economic Research (IRER), Moscow, Russia \\ LLC «Elektra», Yekaterinburg, Russia
}

The purpose of the study is to analyze the main tasks and activities of state and regional government bodies in the implementation of regional programs and activities in the field of energy conservation and energy efficiency.

The methodological basis of the study is the study of measures to improve the efficiency of energy resources use.for this purpose, a comparative analysis and classification are carried out. The information base of the study is based on the regulatory documents of the Russian Federation in the field of energy efficiency. 
Research result. The article analyzes the formation of regional and municipal target programs to improve the energy efficiency of the economy. Methods of low-cost measures for solving energy efficiency issues are presented: legal, administrative, and technological. Special attention is paid to the need to coordinate interaction in the joint activities of public administration bodies and regional structures, regardless of their industry and departmental affiliation and organizational and legal forms.

The research perspective is further research and in-depth analysis of regional measures to improve energy efficiency in order to determine the optimal and cost-effective measures for summarizing and developing modern regulatory documents.

Key words: coordination; development; region; resources; energy; energy efficiency; management.

Введение. Развитие промышленности и экономическое развитие государства в целом, увеличение темпов роста ВВП неизбежно влечет за собой увеличение спроса на энергетические ресурсы, что в свою очередь вызывает необходимость совершенствования самой системы обеспечения необходимыми ресурсами и осуществление мероприятий по повышению эффективности их использования.

Темп роста промышленного производства в Российской федерации, начиная с 2014 г., составляет около $2,5 \%$ ежегодно [1]. Индекс промышленного производства (далее - ИПП), исчисляемый в триллионах рублей, с учетом уровня инфляции, равного 3,98\% в 2020 г., означает рост ИПП, отрицательный для продукции, потребляемой на внутреннем рынке РФ, и положительный - для экспорта при неизменной цене товара в иностранной валюте. Исходя из только этих цифр, можно рассчитать и спланировать: что выгоднее - производить и потреблять внутри страны, а что и сколько производить на экспорт.

При расчете экономической выгоды от принятия мер по повышению эффективности использования энергетических ресурсов и совершенствованию системы обеспечения этими ресурсами необходимо, кроме затрат на проводимые мероприятия и приобретение оборудования, также учитывать прочие расходы (пошлины, логистика, налоги и т.п.), а также потери доходов другими субъектами экономики, в том числе региональных и федерального бюджетов в виде неначисленных налогов.
В ряде регионов (Ярославль [2], Пенза [3] и др.) рост стоимости энергетических ресурсов и затрат на их оплату значительно опережает темпы экономического развития региона, что приводит к снижению рентабельности продукции и конкурентоспособности предприятий. Также существует тенденция смещения промышленного сектора в центральный регион, в результате которой растет себестоимость продукции. Например, доставка из Москвы в регионы в 2-3 раза дороже, чем в обратном направлении.

В отличие от энергосбережения, подразумевающего уменьшение объема используемых энергоресурсов при сохранении полезного результата их использования, энергетическая эффективность является комплексной характеристикой, описывающей особенности отношения полезного результата от использования энергоресурсов к затратам энергетических ресурсов в целях получения данного результата (полезного эффекта). Увеличение коэффициента энергетической эффективности при неизменном количестве затрат энергоресурсов при прочих равных условиях влечет увеличение количества результата (полезного эффекта).

Эффективное использование энергоресурсов - один из ключевых аспектов развития общества. Еще в 1879 г. в «Докладе Городской Управы по V отделению №405» [4] приведен расчет эффективности применения электрического освещения по сравнению с газовым. В этом же докладе указывается на необходимость применения проводящей электропроводящей смазки в приборах электрического освещения. 
Один из первых в мировой истории пример энергоэффективных мероприятий 1898 г. приведен в «Utilization of light in residential premises» [5]. В данной статье изложен сравнительный анализ светового отражения материалов разного цвета. Показано, что «при соответственном выборе цвета и материала стен, потолков, обоев и т.д. освещаемых помещений можно достигнуть значительной экономии» (стилистика сохранена).

Внедрение энергосберегающих технологий и техническое перевооружение выгодно, в первую очередь, самим генерирующим и прочим отраслям промышленности и производствам, так как снижение энергоемкости выпускаемой продукции влечет за собой снижение себестоимости продукции, возможный рост производительности труда и увеличение прибыли при прочих равных условиях.

В свою очередь, снижение себестоимости выпускаемой продукции, а следовательно, повышение конкурентоспособности продукции на внутреннем и на внешнем рынках является важнейшим условием сохранения и развития предприятия. Развитие регионального производственного сектора, в свою очередь, обеспечивает экономический рост регионов и России в целом.

Задача руководства предприятий и региона в решении задач повышения энергоэффективности заключается в определении и разработке мероприятий по привлечению финансирования или инвестиций для этих нужд, а также проведении работ по организации взаимодействия отраслевых видов деятельности регионов.

Федеральный закон №261-Ф3 [6] обязывает органы государственной власти субъектов Российской Федерации и органы местного самоуправления осуществлять мероприятия по разработке и реализации региональных программ в области энергосбережения и повышения энергетической эффективности. При этом разрабатываемые программы должны включать в себя как целевые показатели и перечень обязательных мероприятий по энергосбережению и повышению энергетической эффективности и сроки их проведения, так величину полученного эффекта в натуральном и стоимостном выражении.

Постановлением Правительства Российской Федерации от 31.12.2009 г. №1225
«О требованиях к региональным и муниципальным программам в области энергосбережения и повышения энергетической эффективности» [7] определено, что региональные и муниципальные программы в области энергосбережения и повышения энергетической эффективности должны содержать:

- перечень и методику расчета значений целевых показателей (в том числе общие, в государственном секторе, в жилищном фонде, в промышленности, энергетике и системах коммунальной инфраструктуры, в транспортном комплексе) в области энергосбережения и повышения энергетической эффективности;

- перечень и сроки выполнения мероприятий по энергосбережению и повышению энергетической эффективности, проведение которых возможно с использованием внебюджетных средств.

В соответствии с Постановлением Правительства Российской Федерации от 18.12.2014 г. №1412 «О подготовке и распространении ежегодного государственного доклада о состоянии энергосбережения и повышении энергетической эффективности в Российской Федерации» [8] аналитическая информация о достигнутых результатах и мерах, принимаемых в целях реализации государственной политики в области энергосбережения и повышения энергетической эффективности, в том числе с детализацией по субъектам Российской Федерации, ежегодно отражается в Государственном докладе о состоянии энергосбережения и повышении энергетической эффективности в Российской Федерации.

Каждый регион обладает собственным потенциалом повышения энергоэффективности. С учетом специфики каждого региона, включая географическое положение, наличие и уровень развития промышленности, плотность населения, развитие жилищно-коммунального сектора, наличие собственных (региональных) источников энергии и т.п., определение и выбор реальных к исполнению, наиболее оптимальными и окупаемыми мероприятиями являются юридические, административные и технологические методы.

Региональные и муниципальные целевые программы по повышению энергоэффективности различаются по целям и задачам, мас- 
штабности охвата, объемам финансирования, времени реализации и ожидаемым результатам.

Существующие в настоящее время различные советы и комиссии по реализации региональных программ не имеют надлежащих полномочий и рычагов управления для решения проблем повышения энергоэффективности.

Самым энергоемким потребителем являются секторы «металлургия» и «электроэнергетика». Это, как правило, градообразующие предприятия, своевременно поменявшие энергоемкое оборудование на энергоэффективное.

Сектор «промышленные предприятия»: замена оборудования - высокозатратное мероприятие, окупаемость которого оценивается десятилетиями. Большинство этих предприятий негосударственные, а средства на модернизацию можно взять только из прибыли.

Большой сектор - муниципалитеты. С большой прозрачностью и контролем их бюджетов возможны только малозатратные мероприятия по повышению энергоэффективности, а также экономия муниципалитетами бюджетных средств не мотивирует участников процесса.

Например, муниципалитету необходимо в год обучить 5000 школьников. В бюджет муниципалитета заложена цена энергоресурса на единицу результата (годовое обучение школьника). Деньги необходимо потратить только целевым назначением. Экономия средств не приводит к прямой выгоде муниципалитета: средства должны быть возвращены в бюджет, а это приведет к снижению выделяемых средств на последующий год. Такие примеры повсеместны.

Действующая система энергоменеджмента отрасли и производства, прежде всего, ориентирована на решение отдельных отраслевых или производственных задач по энергоэффективности.

В большинстве случаев объекты региональных программ по повышению энергоэффективности выполняют различные функции и, следовательно, решают различные задачи при разработке и проведении энергоэффективных мероприятий. Эти интересы могут быть несопоставимы и противоречивы. Ярким примером являются диаметрально противоположные интересы предприятий в сфере генерации и конечных потребителей энергоресурсов. В результате возникает конфликт интересов в обеспечении согласованности действий.

Большинство планируемых технологических мероприятий требует наличия и постоянного притока финансового капитала, в том числе инвестиций. Недостаток финансирования мероприятий по энергосбережению и повышению энергетической эффективности остается одной из главных проблем, препятствующих росту энергоэффективности экономик российских регионов. При этом ряд мероприятий по энергосбережению и повышению энергетической эффективности фактически не требует финансовых вложений и технологической установки (замены) энергоэффективного оборудования. Первоочередными к применению должны быть методы, которые сразу и впоследствии дадут наибольший эффект в натуральном (количественном) и стоимостном выражении. От микроэкономики — к макроэкономике.

Такими малозатратными и реальными к исполнению мероприятиями по повышению эффективности использования энергетических ресурсов являются:

1) юридические:

- применение низких цен на энергоресурсы;

- понижающие льготные тарифы;

— закупка энергоресурсов по оптовым ценам;

- смена поставщика;

- заключение энергосервисных контрактов как способ привлечения бюджетов сторонних организаций и получение прибыли от экономии;

- привлечение организаций банковского сектора к льготному кредитованию проектов, связанных с повышением энергоэффективности;

- законодательная защита инвесторов и совершенствование системы налогообложения инвестиционных проектов для привлечения инвестиций;

- лизинг, другие;

2) административные (кадровые и организационные) мероприятия:

- энергоменеджмент и оптимизация технологических процессов при производстве продукции и оказании услуг, логистика;

- назначение и дальнейшее повышение квалификации лиц, ответственных за обес- 
печение мероприятий по энергосбережению и повышению энергоэффективности;

- изучение накопленного в России и в других странах опыта повышения энергоэффективности и энергосбережения;

- обучение и воспитание в сотрудниках организаций и населения чувства ответственности за выполнение поставленных задач;

- агитация и информирование сотрудников организаций и населения о целях, задачах и способах энергосбережения и повышения энергоэффективности,

- локальное управление спросом на энергоносители (децентрализация систем отопления и освещения, оптимизация распорядка работы организации, введение графиков включения/отключения отопления и освещения);

- применение мотивирующих методов и механизмов (использование соревновательного метода и т.п.);

3) технологические мероприятия:

- своевременное обслуживание источников энергии;

- выявление утечек, несанкционированных подключений; мера);

- каскадное отключение, (как временная

- снижение потерь (применение электротехнической смазки, снижение сопротивления и др.);

- своевременный клининг окон, светильников, вентиляционных систем;

- утепление и герметизация зданий;

- управление эффективностью существующего оборудования при сохранении результата функционирования данного оборудования, в том числе контроль технического состояния и техническое обслуживание с периодичностью и в объеме, указанном в технической документации; энергии;

- переход на альтернативный источник

- аккумуляция энергии (тепловой, электрической).

Заключение. Необходимо четкое законодательное определение и разграничение полномочий, обязанностей и ответственности между федеральными, региональными органами исполнительной власти и органами местного самоуправления в сфере эффективности использования энергетических ре- сурсов. При реализации региональных программ и мероприятий в области энергосбережения и энергоэффективности органы государственного и регионального управления должны координировать функционирование механизма взаимодействия в совместной деятельности органов государственного управления и структур региона, независимо от их отраслевой и ведомственной принадлежности и организационно-правовых форм.

\section{Литература}

1. Распоряжение Правительства Российской Федерации от 06.06.2020 г. №1512-р «Об утверждении Сводной стратегии развития обрабатывающей промышленности Российской Федерации до 2024 года и на период до 2035 года» [Электронный ресурс]. — Peжим доступа: http://publication.pravo.gov.ru/ Document/View/0001202006100007 (Дата обращения: 25.09.2020).

2. Электронный фонд правовой и нормативно-технической документации [Электронный ресурс]. - Режим доступа: http://docs. cntd.ru/document/446229427 (Дата обращения: 14.11.2020).

3. Электронный фонд правовой и нормативно-технической документации [Электронный ресурс]. - Режим доступа: http://docs2. kodeks.ru/document/424055906 (Дата обращения: 11.11.2020).

4. Электрическое освещение моста Императора Александра II в г. С.-Петербурге. Электричество [Электронный ресурс]. 1880. - №2. - С. 24. - Режим доступа: https://www.booksite.ru/elektr/1880/1880_02. pdf (Дата обращения: 12.11.2020).

5. Утилизация света в жилых помещениях. Электричество [Электронный ресурс]. 1898. - №20. - С. 285. - Режим доступа: https://www.booksite.ru/elektr/1898/1898_20. pdf (Дата обращения: 27.10.2020).

6. Федеральный закон от 23.11.2009 г. №261-Ф3 «Об энергосбережении и о повышении энергетической эффективности и о внесении изменений в отдельные законодательные акты Российской Федерации». Сб. «Собрание законодательства РФ». - М., 2009. — №48. - С. 5711-5824.

7. Постановление Правительства Российской Федерации от 31.12.2009 г. №1225 
«О требованиях к региональным и муниципальным программам в области энергосбережения и повышения энергетической эффективности» [Электронный ресурс]. - Режим доступа: http://base.garant.ru/12172853/ (Дата обращения: 11.11.2020).

8. Постановление Правительства Российской Федерации от 18.12.2014 г. №1412 «О подготовке и распространении ежегодного государственного доклада о состоянии энергосбережения и повышении энергетической эффективности в Российской Федерации» [Электронный ресурс]. - Режим доступа: http://www.garant.ru/products/ipo/prime/ doc/70726682/ (Дата обращения: 10.11.2020).

\section{References}

1. Rasporjazhenie Pravitel'stva Rossijskoj Federacii ot 06.06.2020 g. №1512-r «Ob utverzhdenii Svodnoj strategii razvitija obrabatyvajushhej promyshlennosti Rossijskoj Federacii do 2024 goda i na period do 2035 goda» [Order of the Government of the Russian Federation of 06.06.2020 №1512-R «On approval of the Consolidated strategy for the development of the manufacturing industry of the Russian Federation until 2024 and for the period up to 2035»] [Jelektronnyj resurs]. - URL: http://publication.pravo.gov.ru/ Document/View/0001202006100007 (Date accessed: 25.09.2020).

2. Jelektronnyj fond pravovoj i normativnotehnicheskoj dokumentacii [Electronic Fund of legal and regulatory and technical documentation] [Jelektronnyj resurs]. — URL: http://docs. cntd.ru/document/446229427 (Date accessed: 14.11.2020).

3. Jelektronnyj fond pravovoj i normativnotehnicheskoj dokumentacii [Electronic Fund of legal and normative-technical documentation] [Jelektronnyj resurs]. — URL: http://docs2. kodeks.ru/document/424055906 (Date accessed: 11.11.2020).

4. Jelektricheskoe osveshhenie mosta Imperatora Aleksandra II v g. S.-Peterburge. Jelektrichestvo [Electric lighting of the bridge of Emperor Alexander II in St. Petersburg. Electricity] [Jelektronnyj resurs]. — 1880. №2. - P. 24. - URL: https://www.booksite. ru/elektr/1880/1880_02.pdf (Date accessed: 12.11.2020).

5. Utilizacija sveta $\mathrm{v}$ zhilyh pomeshhenijah. Jelektrichestvo [Light utilization in residential areas. Electricity] [Jelektronnyj resurs]. 1898. — №20. — P. 285. — URL: https://www. booksite.ru/elektr/1898/1898_20.pdf (Date accessed: 27.10.2020).

6. Federal'nyj zakon ot 23.11.2009 g. №261$\mathrm{FZ}$ «Ob jenergosberezhenii i o povyshenii jenergeticheskoj jeffektivnosti i o vnesenii izmenenij V otdel'nye zakonodatel'nye akty Rossijskoj Federacii» [Federal law of 23.11.2009 №261FZ «On energy saving and on increasing energy efficiency and on amendments to certain legislative acts of the Russian Federation»]. - Sb. «Sobranie zakonodatel'stva RF». - Moscow, 2009. — №48. — Pp. 5711-5824.

7. Postanovlenie Pravitel'stva Rossijskoj Federacii ot 31.12.2009 g. №1225 «O trebovanijah k regional'nym i municipal'nym programmam v oblasti jenergosberezhenija i povyshenija jenergeticheskoj jeffektivnosti» [Decree of the Government of the Russian Federation №1225 of 31.12.2009 «On requirements for regional and municipal programs in the field of energy saving and energy efficiency improvement»] [Jelektronnyj resurs]. — URL: http://base.garant.ru/12172853/ (Date accessed: 11.11.2020).

8. Postanovlenie Pravitel'stva Rossijskoj Federacii ot 18.12.2014 g. №1412 «O podgotovke i rasprostranenii ezhegodnogo gosudarstvennogo doklada o sostojanii jenergosberezhenija i povyshenii jenergeticheskoj jeffektivnosti v Rossijskoj Federacii» [Decree of the Government of the Russian Federation №1412 of 18.12.2014 «On preparation and distribution of the annual state report on the state of energy saving and energy efficiency improvement in the Russian Federation»)] [Jelektronnyj resurs]. URL: http://www.garant.ru/products/ipo/prime/ doc/70726682/ (Date accessed: 10.11.2020). 


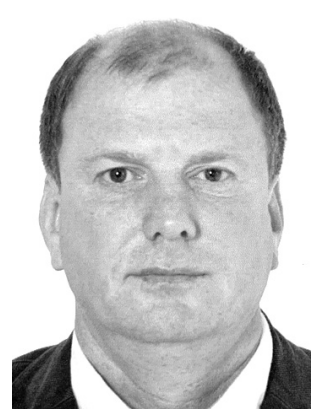

Полетаев Илья Юрьевич - кандидат экономических наук, старший научный сотрудник Института региональных экономических исследований (ИРЭИ), Генеральный директор Общества с ограниченной ответственностью «Электра».

Poletaev Ilya Yurievich - Candidate of Economic Sciences, Senior Researcher, Institute of Regional Economic Research (IRER), General Director of Limited Liability Company «Elektra».

620010 , г. Екатеринбург, ул. Альпинистов, 57 литер «О»

57 Alpinistov, bld. O, 620010, Yekaterinburg, Russia

E-mail: ip@elektraek.ru

119002, г. Москва, пер. Сивцев Вражек, 29/16

29/16 Sivtsev Vrazhek ln., 119002, Moscow, Russia

E-mail:poletaev1@gmail.com 